Invited review article for $\underline{\text { Science, }}$

to appear in the special issue on neuroscience

Draft, 24 Aug 2005 (RCK)

\title{
Sex Differences in the Brain:
}

\section{Implications for Explaining Autism}

Simon Baron-Cohen, Rebecca C. Knickmeyer, and Matthew K. Belmonte,

Autism Research Centre, Cambridge University, Department of Psychiatry,

Douglas House, 18b Trumpington Road, Cambridge CB2 2AH, UK. 
'Empathizing' is the capacity to predict and to respond to the behavior of agents (usually people) by inferring their mental states and responding to these with an appropriate emotion. 'Systemizing' is the capacity to predict and to respond to the behavior of nonagentive, deterministic systems, by analyzing input-operation-output relations and inferring the rules that govern such systems. At a population level, females are stronger empathizers and males stronger systemizers. The 'extreme male brain' theory posits that autism represents an extreme of the male pattern (impaired empathizing and enhanced systemizing). Here we suggest that specific aspects of autistic neuropathology may also be extremes of typical male neuroanatomy. 
Leaving aside political correctness, there is compelling evidence for sexual dimorphism in the brain, cognition, and behavior (1). In this Viewpoint we review the evidence at all three levels. Classic autism and Asperger Syndrome (AS) are the two clearest subgroups on the autistic spectrum of conditions, and both affect males more often than females. We conjecture that understanding sex differences in the general population has implications for understanding the causes of autism spectrum conditions.

\section{The E-S theory of psychological sex differences}

Although males and females do not differ in general intelligence, specific cognitive performance-tasks does-reveal sex differences. Differences favoring males are seen on the mental rotation test (2), spatial navigation including map reading (3), targeting (4), and the Embedded Figures Test (5), though there are conflicting studies regarding the latter (6). Males are also more likely to play with mechanical toys as children (7), and as adults they score higher on engineering and physics problems (8). In contrast, females score higher on tests of emotion recognition (9), social sensitivity (10) and verbal fluency (11). They start to talk earlier than boys (12) and are more likely to play with dolls as children (7). Effect sizes range from small (Cohen's $d=0.2$ for emotion recognition) to large (Cohen's $d=1.3-1.9$ for targeting), with a substantial degree of overlap between male and female distributions even for effects considered large by the conventions of psychology. All these differences exist at the level of populations, not individuals; from such population differences no inferences can or should be made about individuals.

Although these population differences partially arise from eultural-experiential factors, experiments in animals suggest a biological foundation: Male rats perform significantly 
better than females on the radial arm and Morris water maze (13). This sex difference is eliminated by castration of males, or by treating females with testosterone neonatally (14). Human males also commit fewer errors and require less time to complete a "virtual" maze (15). Young male vervet monkeys prefer to play with toy trucks, while young female vervets prefer dolls (16). This finding suggests sex differences in toy preferences in children result, in part, from innate biological differences. Biological contributions to social interest are suggested by studies of human infants: When one-day-old babies are presented with either a live face or a mechanical mobile, girls spend more time looking at the face whilst boys prefer the mechanical object (17).

According to the E-S theory of psychological sex differences, such differences reflect stronger 'systemizing' in males and 'empathizing' in females (18). Systemizing is the drive to analyze a system in terms of the rules that govern the system, in order to predict the behavior of the system. Empathizing is the drive to identify another's mental states and to respond to these with an appropriate emotion, in order to predict and to respond to the behavior of another person. (Other people's emotional states and behavior cannot easily be predicted and responded to using systemizing strategies: Whereas a deterministic system given the same inputs always produces the same outputs, the inputoutput function of a person depends on subtle differences in current and past emotional context, and is practically impossible to parameterize formally).

The E-S theory proposes that psychological sex differences are defined by the difference between the dimensions of empathizing (E) and systemizing (S), and categorizes individual 'brain types' as Type $\mathrm{S}(\mathrm{S}>\mathrm{E}$, more common in males), Type $\mathrm{E}(\mathrm{E}>\mathrm{S}$, more 
common in females), or Type $\mathrm{B}(\mathrm{E}=\mathrm{S}$, in those who are equally proficient at empathizing and at systemizing) (Fig. 1). Data from two questionnaires, the Empathy Quotient (EQ) and the Systemizing Quotient (SQ), reveal the existence of extreme types where $\mathrm{S}>>\mathrm{E}$ or $\mathrm{E}>>\mathrm{S}$ (Fig. 2), and SQ-EQ difference scores (Fig. 3) illustrate the differing profiles of the two sexes. Ongoing studies from our lab confirm the psychometric reliability and validity of these scales (19) and are evaluating how they correlate with performance tests $(20)$.

\section{Sex differences in brain structure}

Although there is a great deal of individual variance in human brain morphometry $(21)$, it is known that the cerebrum as a whole is about $9 \%$ larger in men and is also larger in boys $(21)$ - a difference driven more by white matter than by grey $(22,23)$. Despite the larger total volume of white matter in men (and despite the conflicting studies of sex differences in specific corpus callosum measures (24)), 3D morphometry suggests that the ratio of corpus callosum to total cerebral volume is actually smaller in men (22). This is consistent with the findings that increased brain size predicts decreased interhemispheric connectivity (25), and that larger brains come with proportionately smaller corpora callosa in humans (26) and other species (27). Reports of anatomically localized cerebral sexual dimorphism are less consistent (28), but the male amygdala undergoes an extended period of growth during childhood (29); it is larger in boys (30) and may remain larger in men (28). These anatomical differences likely result from differences in

microarchitecture: there are more neurons in the male cerebral cortex (31), and in general these neurons are more densely packed (32), albeit with some regional exceptions (33). 
Overall, greater numbers and denser packing of neurons, together with more intrahemispheric white matter projecting from these neurons, indirectly suggest a pattern of increased local connectivity and decreased inter-hemispheric (or long-range) connectivity in the male brain. Physiological observations, though sparse, seem consistent with this picture: language-related activation in female brains is more bilateral, suggesting greater inter-hemispheric connectivity $(34,35)$, and the single study of gamma-band MEG reports increased phase-locking between frontal and parietal sites in women during cognitive performance, again suggesting greater long-range connectivity (36).

\section{The EMB theory of autism at the psychological level}

An extension of the E-S theory of typical sex differences is the 'extreme male brain' (EMB) theory (37). This proposes that individuals on the autistic spectrum are characterized by impairments in empathizing alongside intact or even superior systemizing. Adults with $\mathrm{AS}^{1}$ are more likely to have a brain of Extreme Type $\mathrm{S}$ (Fig. 2), and are distinguished by their high SQ-EQ difference scores (Fig. 3). Table 1 gives the frequencies of all E-S brain types, in the general population and in people with AS.

Reduced empathy in people with AS is evident in their lower scores on emotion recognition tests (38), the EQ (39), the Friendship and Relationship Quotient (40), and tests of social sensitivity such as the faux pas test (10). Intact or even superior

\footnotetext{
${ }^{1}$ Individuals with AS have normal language ability but nevertheless have the marked
} 
systemizing is seen in their higher scores on the SQ (41), tests of folk physics (42), and the Embedded Figures Test (43) (though it is unclear if the latter is really a test of systemizing or simply a test of good attention to detail). It is also seen in their strong 'obsessions' or areas of narrow interest, which tend to focus on systems (44).

It is clear how the EMB theory might characterize people with AS, but to what extent does the EMB theory apply to the whole autistic spectrum? People with classic autism have empathy deficits, or degrees of 'mindblindness,' in that they are delayed in developing a 'theory of mind' in childhood and joint attention in infancy (45). It is less straightforward to test systemizing in someone with little language or below-average IQ. Nevertheless, characteristic behaviors such as 'insistence on sameness,' repetitive behavior, obsessions with lawful systems (e.g train timetables), islets of ability (e.g. calendrical calculation), precocious understanding of machines, and superior attention to change-detection all involve a strong interest in rule-based prediction, and therefore can be read as signs of hyper-systemizing. It is unclear whether the risk of reduced IQ or language difficulties increases as systemizing becomes so strong that attention is narrowed to understanding just one unique system, making generalization of knowledge irrelevant (46). Of course, such symptoms may reflect other processes than systemizing, and competing hypotheses need to be tested.

\section{The EMB theory of autism at the neuroanatomical level}

Recent hypotheses concerning neural connectivity in the autistic brain postulate an

social difficulties and 'obsessional' narrow interests characteristic of autism. 
exaggerated version of what may also be going on in the typical male brain: a skewed balance between local and long-range connectivity (47-50). Such a connectivity difference could give rise to a deficit in empathizing, because empathy activates brain regions that integrate information from multiple neural sources (51). In autism, furthermore, long-range connectivity during an empathizing task is abnormally low (52). This notion of skewed connectivity is also compatible with strong systemizing, because systemizing involves a narrow attentional focus to local information in order to understand each part of a system, imaging studies are needed to confirm this relationship.

Young children with autism tend to have larger than average heads. MRI morphometry confirms that these large heads contain abnormally large brains, an increase driven more by white matter than grey (53). Though not yet confirmed by in vivo tract-tracing, tThe anatomical distribution of this white-matter hyperplasia suggests it occurs more in shortdistance tracts, whilst internal capsule and corpus callosum are proportionately reduced (54-56). The development of the amygdala in autism likewise seems an extreme of typical male brain development: in children with autism between 18 and 35 months of age, the amygdala is abnormally large, even when corrected for total brain volume (57). This enlargement persists through early childhood $(58,59)$ - exactly during the period of sex-differential amygdala growth in normal boys. By the time children with autism reach adolescence, the enlargement has disappeared (59), and by early adulthood the amygdala in autism is abnormally small $(60,61)$.

In summary, like an exaggeration of typical males, children with autism show enlargement of the cerebral cortex that stems more from white matter than grey, and may 
affect short-distance more than long-distance tracts. Again, like an exaggeration of typical boys, children with autism also show greater growth of the amygdala. Future research will need to map all aspects of autistic neuropathology that are hypermasculinized, as well as consider how to explain those aspects that are not.

\section{Prenatal androgens produce sex differences in brain and behavior}

Which biological mechanisms shape the such-above described sex differences, and may be pushing the autistic brain to develop beyond the typical male? In this section we review evidence for prenatal androgens as a key biological mechanism. Androgens, including testosterone produced by the testes in fetal and neonatal life, act on the brain to produce sex differences in neural structure and function. Testosterone is a small, lipophilic molecule that easily passes through the blood-brain barrier and across cell membranes. The androgen receptor (AR) is a classic steroid receptor found in the cytoplasm. Once bound to testosterone (or its metabolite dihydrotestosterone), the AR enters the nucleus where it binds DNA and affects transcription. Testosterone can also be aromatised to estradiol within the target cell, binding to the estrogen receptor (ER- $\alpha$ or ER- $\beta$ ) and influencing transcription similarly. Testosterone affects neural development by averting programmed cell death, influencing neural connectivity, and altering neurochemical profiles (14). For example, testosterone and estradiol modulate serotonergic and GABAergic transmission, and increase formation of dendritic spines in a process mediated by brain-derived neurotrophic factor (BDNF).

In the fetal primate brain, significant AR binding is observed in the cerebral cortex, cerebellum, mediobasal hypothalamus, amygdala, corpus callosum, and cingulate cortex 
of both sexes. Detectable levels of enzymes that convert testosterone to its active metabolites are also found in these regions (62). ER- $\alpha$ is found in the hypothalamus and amygdala, with lower concentrations also in the cerebral cortex (63). ARs are present as early as the first trimester, with high expression in temporal cortex and other regions (64). AR binding in the developing cerebral cortex is higher in the right frontal lobe and the left temporal lobe in males, an asymmetry not present in females (65). Rats show a sexually dimorphic asymmetry in cortical thickness, dependent on testosterone and possibly related to receptor distribution. Although the literature on anatomical and functional asymmetries in humans is contentious, a number of researchers have suggested that the male brain is more strongly lateralized than the female brain (66). Although information on AR distribution in the human fetal brain is limited, AR distribution may be conserved across species. The single study of ER distribution in the human midgestational fetus shows ER- $\beta$ but no ER- $\alpha$ expression in cortex (67).

In humans, exposure to atypically high levels of prenatal androgens results in masculine behavior and ability patterns (68). For example, females with congenital adrenal hyperplasia $(\mathrm{CAH})$, a genetic condition that elevates fetal testosterone (FT), show 'tomboy' behavior (69). Normal inter-individual variation in prenatal hormone levels, measured in amniotic fluid-or maternal bloød, correlates with later sex-typed behavior (70-73).

All the sexually dimorphic brain regions discussed previously are rich in ARs, and their development therefore may be rather directly affected by testosterone (28), either early in fetal life or later. This raises new questions: if autism is an extreme of the male brain, is 
this the result of elevated FT, abnormalities in ARs or the genes controlling FT, or sexually dimorphic gene expression unrelated to FT? Currently there are six clues that FT may play a role in autism: (1) FT is associated with low ratios of second to fourth digit length (70) and a low digit-length ratio is in turn associated with autism spectrum conditions (71). (2) Girls with CAH manifest more autism-like traits than their unaffected sisters (72). (3) Within normal development, FT is inversely correlated with behaviors that in the extreme would count as diagnostic symptoms for autism: eye contact, vocabulary development, social functioning, and narrow interests (73-75). (4) There is preliminary evidence of somatic hypermasculinisation in autism, though a comprehensive study of this is needed (76). (5) There is precocious puberty in boys with autism. (6) Serotonin levels (49) and BDNF levels are elevated in autism (66) and these are mediated by fetal testestereneFT. A direct test of the FT hypothesis using amniocentesis is underway in our laboratory.

\section{Further work}

Investigation of the EMB theory of autism demands more detailed normative data, especially in the areas of histology and physiology. Does network architecture differ between the sexes, and if so in what ways? What can diffusion tensor imaging reveal about sex differences in white matter topography? What will the application of new methods of functional connectivity analysis reveal about normal sex differences in functional imaging and quantitative EEG and MEG? Do males with more 'female' E-S profiles have more 'female' brain anatomies, and vice versa? And how do these differences in brain structure and dynamics change during development? 
In parallel, the correlation between autism and exaggerated male brain characteristics can be explored by detailed anatomic study of regions that are known to be sexually dimorphic in the normal brain but that have not yet been investigated in the autistic brain, such as the interstitial nuclei of the anterior hypothalamus (INAH) (77). In addition, it will be important to distinguish brain dimorphisms mediated by testosterone from those that arise more directly from genetic factors, or that depend on experience. Evidence for direct genetic effects on brain sexual dimorphism does exist. For example, mice in whom chromosomal sex and gonadal sex do not correspond differ behaviorally in maze learning, and neurochemically in vasopressin innervation of the lateral septum (14). Since $15 \%$ of $\mathrm{X}$-chromosome genes escape $\mathrm{X}$ inactivation in humans (78), $\mathrm{X}$ chromosome gene dosage effects may play a role in such direct genetic effects. Neuroanatomical observations in populations with anomalous sex chromosome variations may prove informative. In addition, it has been suggested that an imprinted $X$ locus may explain sex differences in social and communicative skills, and the male vulnerability to social and communicative impairments (79).

How the EMB theory applies to females with autism is also of interest: if a male brain is a risk factor for autism this may explain the lower prevalence in females. If the EMB theory does apply to autism, might it apply more broadly to a range of neurodevelopmental conditions that affect males more than females? Lastly, even if the EMB theory can explain some core characteristics of autism, it will be important to establish which other comorbid characteristics require different explanations. 


\section{Conclusion}

The EMB theory was first formulated by Hans Asperger as a clinical anecdote more than sixty years ago. In the last decade has it been reformulated to be psychologically testable. Using psychometric definitions of the typical male and female brain, people with autism spectrum conditions show an exaggeration of the male profile. Evidence reviewed above suggests this may also apply to aspects of autistic neuropathology. The challenge ahead will be to test this theory across the whole autistic spectrum. 
Table 1. Classifications of brain type based upon percentiles ( 80$)$

\begin{tabular}{|c|c|c|c|c|c|}
\hline Brain Type & Extreme E & $\mathbf{E}$ & B & $\mathbf{S}$ & Extreme $S$ \\
\hline \multirow[t]{2}{*}{ Brain Sex } & Extreme & Female & Balanced & Male & Extreme \\
\hline & female & & & & male \\
\hline Defining & $\mathbf{S}<<\mathbf{E}$ & $\mathbf{S}<\mathbf{E}$ & $\mathbf{S} \approx \mathbf{E}$ & $\mathbf{S}>\mathbf{E}$ & $\mathbf{S} \gg \mathbf{E}$ \\
\hline \multicolumn{6}{|l|}{ Characteristic } \\
\hline percentile (per) & per $<2.5$ & $2.5 \leq$ per $<35$ & $35 \leq$ per $<65$ & $65 \leq$ per $<97.5$ & per $\geq 97.5$ \\
\hline Female \% & 4.3 & 44.2 & 35.0 & 16.5 & $\mathbf{0}$ \\
\hline Male \% & $\mathbf{0}$ & 16.7 & 23.7 & 53.5 & 6.1 \\
\hline AS/HFA \% & $\mathbf{0}$ & $\mathbf{0}$ & 12.8 & 40.4 & 46.8 \\
\hline
\end{tabular}


Fig. 1: The Empathizing-Systemizing model of sex differences at the psychological level attached 
Fig. 2: Cumulative distribution function $\left(\Sigma_{D}\right)$ of $D$. This graph shows that the difference scores (D) between EQ and SQ significantly differentiate the three populations (males, females, and individuals with a diagnosis of AS/HFA) (80)

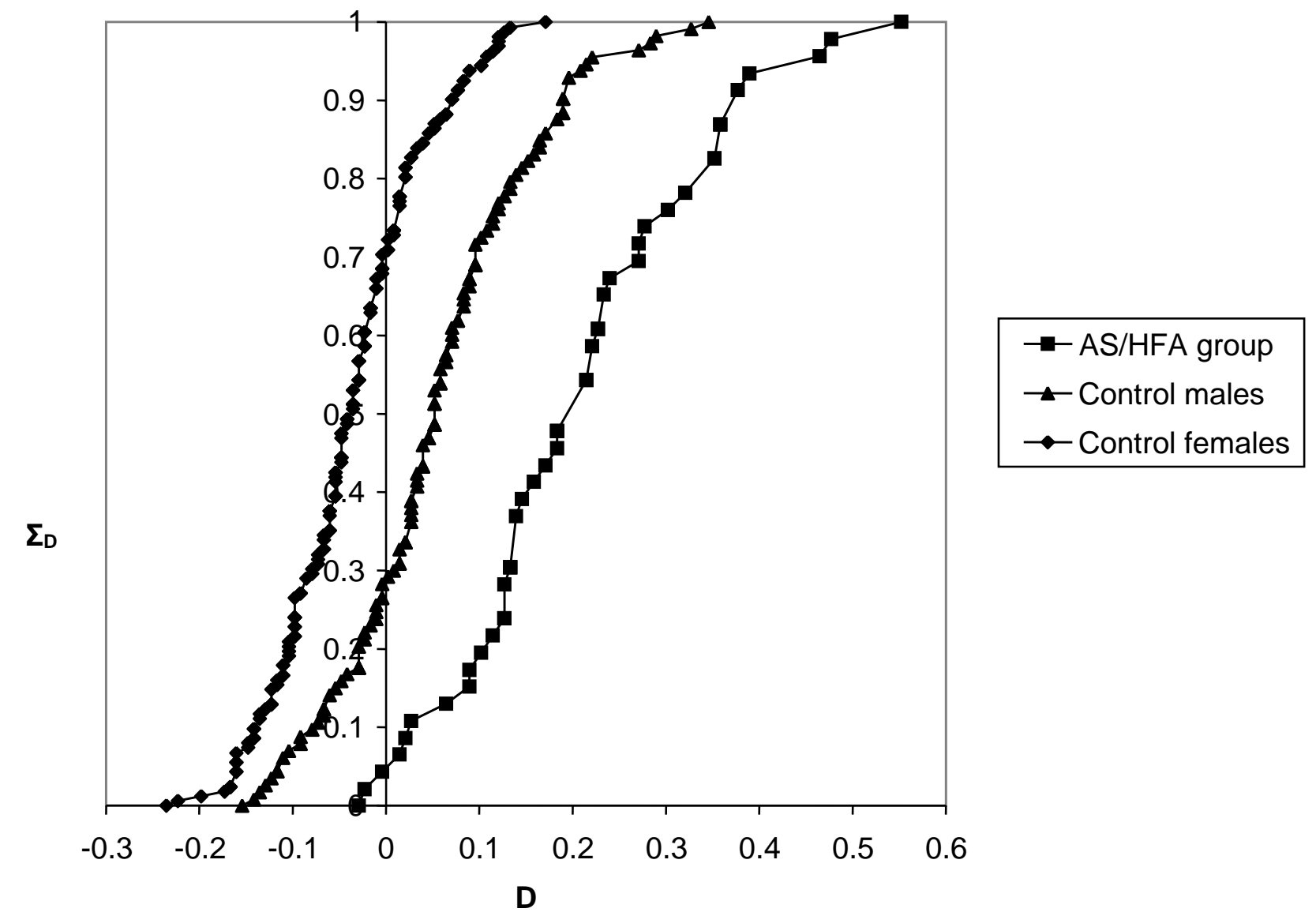


Fig. 3: SQ scores versus EQ scores for all participants with the boundaries for the different brain types $(80)$.

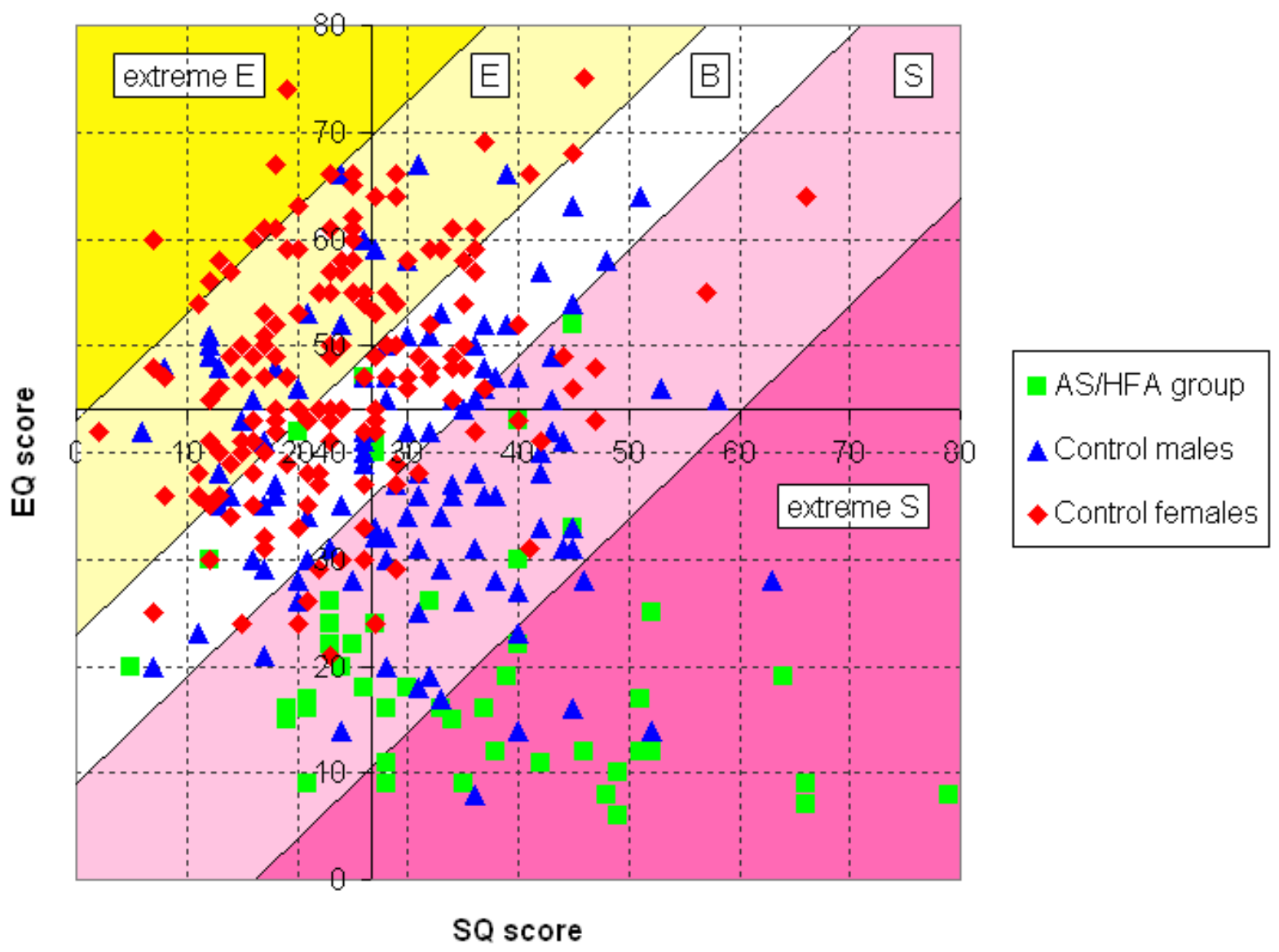

${ }^{2}$ SBC and RCK were funded by the MRC and the Nancy Lurie Marks Family Foundation during the period of this work. We are grateful to Sally Wheelwright, Johnny Lawson and Nigel Goldenfeld for their help in producing the figures, and for comments on this paper. 


\section{References:}

1. D. Kimura, Sci. Am. 267, 119 (1992).

2. R. N. Shephard, J. Metzler, Science 171, 701 (1971).

3. D. Kimura, Sex and Cognition (MIT Press, Cambridge, MA, 1999).

4. $\quad$ N. V. Watson, D. Kimura, Personality Individ. Diff. 12, 375 (1991).

5. H. A. Witkin, R. B. Dyk, H. F. Faterson, D. G. Goodenough, S. A. Karp, Personality through perception (Harper \& Row, New York, 1962).

6. J. S. Hyde, E. R. Geiringer, M. W. Yen, Multivariate Behav.Res 10, 289 (1975).

7. M. Hines, L. S. Allen, R. A. Gorski, Brain Res. 579, 321 (1992).

8. J. Lawson, S. Baron-Cohen, S. Wheelwright, J. Autism Dev. Disord. 34, 301 (2004).

9. $\quad$ E. B. McClure, Psychol Bull 126, 424 (May, 2000).

10. S. Baron-Cohen, M. O'Riordan, R. Jones, V. Stone, K. Plaisted, J. Autism Dev. Disord. 29, 407 (1999).

11. J. S. Hyde, M. C. Linn, Psychol. Bull. 104, 53 (1988).

12. L. Fenson et al., Mon. Soc. Res. Child Dev. 59 (1994).

13. R. L. Roof, Q. Zhang, M. M. Glasier, D. G. Stein, Behav. Brain. Res. 57, 47 (1993).

14. G. De Vries, R. B. Simerley, in Hormones, Brain and Behaviour :Development of Hormone-Dependent Neuronal Systems D. W. Pfaff et al., Eds. (Academic Press, San Diego, 2002), vol. IV, pp. 137.

15. S. D. Moffat, E. Hampson, D. H. Lee, Brain 121, 2369 (1998).

16. G. M. Alexander, M. Hines, Evol. Hum. Behav 23, 467 (2002).

17. J. Connellan, S. Baron-Cohen, S. Wheelwright, A. Ba'tki, J. Ahluwalia, Infant Behav. Dev. 23, 113 (2001).

18. S. Baron-Cohen, The Essential Difference: Men, Women and the Extreme Male Brain (London, Penguin, 2003).

19. A. Wakabayashi et al., (submitted).

20. J. Billington, S. Baron-Cohen, S. Wheelwright, A. Parekh, C. Hoxley, (submitted).

21. J. N. Giedd et al., J. Comp. Neurol. 366, 223 (1996).

22. J. S. Allen, H. Damasio, T. J. Grabowski, J. Bruss, W. Zhang, Neurolmage 18, 880 (2003).

23. E. Luders et al., NeuroImage 26, 493 (2005).

24. K. M. Bishop, D. Wahlsten, Neurosci. Biobehav. Rev. 21, 581 (1997).

25. J. L. Ringo, R. W. Doty, S. Demeter, P. Y. Simard, Cereb. Cortex 4, 331 (1994).

26. L. Jancke, J. F. Staiger, G. Schlaug, Y. Huang, H. Steinmetz, Cereb. Cortex 7, 48 (1997).

27. J. K. Rilling, T. R. Insel, Neuroreport 10, 1453 (1999).

28. J. M. Goldstein et al., Cereb. Cortex 11, 490 (2001).

29. D. P. Merke et al., J. Clin. Endocrinol. Metab. 88, 1760 (2003).

30. V. S. Caviness, Jr., D. N. Kennedy, C. Richelme, J. Rademacher, P. A. Filipek, Cereb. Cortex 6, 726 (1996).

31. B. Pakkenberg, H. J. G. Gundersen, J. Comp.Neurol. 384, 312 (1997).

32. T. Rabinowicz et al., J. Neuropathol. Exp. Neurol. 61, 46 (2002).

33. S. F. Witelson, I. I. Glezer, D. L. Kigar, J. Neurosci. 15, 3418 (1995).

34. B. Shaywitz et al., Nature 373, 607 (1995). 
35. L. C. Baxter et al., Brain Lang. 84, 264 (2003).

36. S. Braeutigam, S. P. Rose, S. J. Swithenby, T. Ambler, Eur. J. Neurosci. 20, 293 (2004).

37. S. Baron-Cohen, Trends Cogn. Sci. 6, 248 (2002).

38. S. Baron-Cohen, S. Wheelwright, J. Hill, Y. Raste, I. Plumb, J.Child Psychol. Psychiatry 42, 241 (2001).

39. S. Baron-Cohen, S. Wheelwright, J. Autism Dev. Disord. 34, 163 (2004).

40. S. Baron-Cohen, S. Wheelwright, J. Autism Dev. Disord. 33, 509 (2003).

41. S. Baron-Cohen, J. Richler, D. Bisarya, N. Gurunathan, S. Wheelwright, Philos.Trans. R. Soc. London 358, 361 (2003).

42. S. Baron-Cohen, S. Wheelwright, V. Scahill, J. Lawson, A. Spong, J. Dev. Learn. Disord. 5, 47 (2001).

43. T. Jolliffe, S. Baron-Cohen, J. Child Psychol. Psychiatry 38, 527 (1997).

44. S. Baron-Cohen, S. Wheelwright, Br. J. Psychiatry 175, 484 (1999).

45. S. Baron-Cohen, Mindblindness: an essay on autism and theory of mind (Boston, MIT Press/Bradford Books, 1995).

46. S. Baron-Cohen, Arch. Dis. Child. (in press).

47. M. K. Belmonte et al., J. Neurosci. 24, 9228 (2004).

48. E. Courchesne, K. Pierce, Curr. Opin. Neurobiol. 15, 225 (2005).

49. M. K. Belmonte et al., Mol. Psychiatry 9, 646 (2004).

50. M. A. Just, V. L. Cherkassky, T. A. Keller, N. J. Minshew, Brain 127, 1811 (2004).

51. K. N. Ochsner et al., J Cogn. Neurosci. 16, 1746 (2004).

52. D. Welchew et al., Biol. Psychiatry 57, 991 (2005).

53. E. Courchesne, E. Redcay, D. P. Kennedy, Curr. Opin. Neurol. 17, 489 (2004).

54. M. R. Herbert et al., Ann. Neurol. 55, 530 (2004).

55. B. Egaas, E. Courchesne, O. Saitoh, Arch. Neurol. 52, 794 (1995).

56. J. D. Lewis, E. Courchesne, paper presented at the 4th International Meeting for Autism Research, Boston 2005.

57. M. W. Mosconi et al., paper presented at the 4th International Meeting for Autism Research, Boston 2005.

58. B. F. Sparks et al., Neurology 59, 184 (2002).

59. C. M. Schumann et al., J. Neurosci. 24, 6392 (2004).

60. E. H. Aylward et al., Neurology 53, 2145 (1999).

61. D. C. Rojas et al., Am. J. Psychiatry 161, 2038 (2004).

62. S. A. Sholl, R. W. Goy, K. L. Kim, Endocrinology 124, 627 (1989).

63. S. M. Pomerantz, T. O. Fox, S. A. Sholl, C. C. Vito, R. W. Goy, Endocrinology 116, 83 (1985).

64. R. J. Handa, P. B. Connolly, J. A. Resko, Endocrinology 122, 1890 (1988).

65. S. A. Sholl, K. L. Kim, Brain Res. 516, 122 (1990).

66. A. B. Wisniewski, Psychoneuroendocrinology 23, 519 (1998).

67. M. R. Herbert et al., Brain 128, 213 (Jan, 2005).

68. S. A. Berenbaum, Endocrinol. Metab. Clin. North Am. 30, 173 (2001).

69. M. Hines, F. R. Kaufman, Child Dev. 65, 1042 (1994).

70. S. Lutchmaya, S. Baron-Cohen, P. Raggatt, J. T. Manning, Early Hum. Dev. 77, 23 (2004).

71. J. Manning, S. Baron-Cohen, S. Wheelwright, G. Sanders, Dev. Med. Child Neurol. 43, 160 (2001). 
72. R. Knickmeyer et al., (submitted).

73. G. Grimshaw, G. Sitarenios, J. Finegan, Brain Cogn. 29, 85 (1995).

74. S. Lutchmaya, S. Baron-Cohen, Infant Behav. Dev. 25, 319 (2002).

75. S. Lutchmaya, S. Baron-Cohen, P. Raggatt, Infant Behav. Dev. 25, 327 (2002).

76. A. Tordjman, P. Ferrari, V. Sulmont, M. Duyme, P. Roubertoux, Am. J. Psychiatry 154, 11 (1997).

77. L. S. Allen, M. Hines, J. E. Shryne, R. A. Gorski, J. Neurosci. 9, 497 (1989).

78. L. Carrel, A. A. Cottle, K. C. Goglin, H. F. Willard, Proc. Natl. Acad. Sci. U.S.A. 96, 14440 (1999).

79. D. H. Skuse, Pediatr. Res. 47, 9 (2000).

80. N. Goldenfeld, S. Baron-Cohen, S. Wheelwright, Int. J. Clin. Neuropysch. (in press). 